\title{
Assessing communication on sexual and reproductive health issues among high school students with their parents, Bullen Woreda, Benishangul Gumuz Region, North West Ethiopia
}

\author{
Desalegn Gebre Yesus ${ }^{1}$, Mesganaw Fantahun ${ }^{1}$
}

\begin{abstract}
Background: "Adolescents "and "young people "are defined by WHO as the age group 10-19 years and 10-24 years, respectively. Young people make up over one - quarter of the world's population. Neglecting this population has a major implication on sexual and reproductive behaviors as they develop into adults. The health threats for adolescents today are predominantly behavioral rather than biomedical and more of today's adolescents are involved in health behaviors with potential for serious consequences. Hence, it is important to understand the exposure of school students to sexual and reproductive health knowledge and skills at different places including home.

Objective: To assess the level and factors influencing communication between school students and parents on sexual and RH issues.

Methods: A cross-sectional survey using self-administered questionnaire and supplemented by focus group discussion was conducted in January 2006 at Bullen Woreda preparatory and high schools in northwest Ethiopia.

Results: A total of 412 young people participated in the study. Of these, 284(68.9\%) were males and the rest $29.1 \%$ females About $13 \%$ of the respondents were sexually active.

School was mentioned as the most common source of information for sexual and reproductive health issues followed by friends. Three hundred sixty two $(88 \%)$ respondents believed that it is important to discuss sexual and reproductive health issues/matters with parents. However, only $119(28.9 \%)$ of them discussed on two or more SRH topics with their parents. A high proportion of both male (78\%) and female (72\%) students preferred to discuss sexual and reproductive health issues with peers compared to less than $27 \%$ who prefer to discuss with parents.

Conclusions: Although the majority of the students think discussion on sexual and reproductive health issues is important, they prefer to discuss with peers as this makes them more comfortable. Thus, it is essential to improve the sexual and Reproductive Health knowledge of school students to enhance peer influence positively and improve parent student communications through targeted family life education activities among students and parents. [Ethiop. J. Health Dev. 2010;24(2):89-95]
\end{abstract}

\section{Introduction}

"Adolescents" and "young people" are defined by WHO as the age group of 10-19 years and 10-24 years, respectively. The onset of adolescence more or less coincides with puberty and is often influenced by manifestation of the latter. Young people make up over one -quarter of the world's population. Almost 1.4 billion young people live in developing countries today (1). This implies that the group deserves due attention and neglecting this population has a major implication on sexual and reproductive behaviors as they grow into adults (2).

The health threats for adolescents today are predominantly behavioral rather than biomedical and more of today's adolescents are involved in health behaviors with potential for serious consequences (3).

Communication about sexuality and sexual matters is more important perhaps now than any other time. This is because adolescents are affected with the burden of unwanted pregnancy and its complication, HIV/AIDS/STI, and other sexual and reproductive illhealth to a greater extent (4). Parent-adolescent communication regarding sexuality is perceived by many to be effective means of encouraging adolescents to adopt responsible sexual behaviors (4).

A study in Butajira, south central Ethiopia showed that only $5.6 \%$ and $2.6 \%$ of students reported talking about sexuality with friends and family members, respectively (5). Another study also showed that students were able to talk openly about sexuality firstly with friends $(90.8 \%)$, and $\mathrm{girl} / \mathrm{boy}$-friend $(80.5 \%)$ and least with teachers $(18.7 \%)$, parents $(17.8 \%)$ or priests $(8.9 \%)(6)$.

Communication between parents and their children about sexual issues and impact of this communication on adolescents' sexual behavior has been one important research area which helps to improve the prevention of sexual and reproductive health problems and promote educational programs that meet the needs and concerns of youth (7).

This cross-sectional study was conducted to assess the level and factors influencing communication between school students and parents on sexual and RH issues.

\section{Methods}

Study design: This cross sectional study employed quantitative and qualitative designs and was conducted in 
January, 2006.

Study area and population: The study was carried out among high school students complemented by focus group discussion with parents, in Bullen Woreda, Benishangul Gumuz Regional state, northwest Ethiopia.

Bullen Woreda is found $583 \mathrm{KMs}$ away from Addis Ababa. The study population includes all students from grade 9 to grade 12 attending Bullen secondary and preparatory schools. The total numbers of the students were 1140. Students aged 13-24, unmarried who were attending secondary (grades 9-10) and preparatory schools (grades 11-12) at the time of data collection were included in the study.

Inclusion criteria: Those aged 13-24 years, unmarried who were attending secondary and preparatory schools during the day time were included. This age group was taken as a target population by considering the minimum age of secondary school students and the maximum age of young people as defined by WHO.

Exclusion criteria: Those students who were married and aged 24 years old and above were excluded from the study.

Sample size calculations: The sample size for the study was calculated using EPI INFO version 6 statistical software. Using the assumption that the proportion of parent adolescent communicating on reproductive issue about STD/HIV/AIDS to be 50\% (8), 95\% CI, 5\% marginal error, and $10 \%$ non response rate and adding a $10 \%$ non response rate, a total of 422 students were required for the study. The sampling unit was taken from each class based on the proportion to the size of each grade.

Data collection: Six people, who completed grade 12, fluent in Amharic and the local language, were recruited to facilitate data collection using pretested self administered anonymous questionnaires. Questions that can address the objective of the study were gathered and adapted from previous similar studies and other materials. Focus group discussions were carried out among purposively selected parents (both mothers and fathers) who had young people age 13-24 years. The discussion of the mothers was moderated by a trained female nurse and that of the fathers was lead by the principal investigators. A semi structured questions guide was used to lead the discussion.

Three supervisors coordinated activities, checked the data for consistency and completeness.

Training was given for all who facilitated the data collection process. It included a briefing on the general objective of the study; discussing the content of the questionnaires in detail, the methodology in relation to reaching the intended goals, and more importantly on how to keep confidentiality and privacy.

Pre testing: The questionnaires and FGD guide was pretested in similar population (among high school and parents), in Debatie Woreda, which is located $35 \mathrm{kms}$ away from the study area after which necessary modification was made.

Data entry and analysis: Data were entered using EPI INFO version 6 by experienced data clerks and analyzed on EPI INFO and SPSS version XII. Data were summarized using frequency, tables and proportion. Chisquared test and Odds Ratio $(95 \% \mathrm{CI})$ were used for assessing significance of associations respectively.

Ethical considerations: The study proposal was approved by the Ethical Clearance Committee of the Medical Faculty of Addis Ababa University. Informed written consent was obtained from each study subject after thorough explanation of the objectives and the procedures of the study. Moreover, the benefit of this study were explained to the study population in that the Regional Health Bureau and other concerned body can utilize the results in improving the reproductive and sexual health of young people. The study population especially of the FGD discussants was also given information on the importance of discussion on sexual matter with adolescents at end of the FGD.

Confidentiality was ensured by making the questionnaires anonymous and avoiding personal identifications.

\section{Results}

A total of $412(97.6 \%)$ respondents were included in the study. Of these $284(68.9 \%)$ were males. The mean age of the respondents was $17.26 \pm 1.53 \mathrm{SD}$ and the majority were Orthodox Christians (Table 1).

Three hundred forty seven (84.2\%) respondents knew about STI/HIV/AIDS. HIV/AIDS was the most commonly known STI $300 \quad(88 \%)$, followed by Gonorrhea 267 (78.3\%).

Most of the respondents 313(76\%) knew when first menstrual period started (menarche), and the reported mean age of menarche was $13.86 \pm 1.5$ SD. Feeling towards first menarche among female respondents include fear, felt sick, felt ashamed which accounted for $84(66.1 \%), 36(28.6 \%), 30(23.8 \%)$, respectively (Fig 1). 
Table 1: Socio-demographic characteristics of school students in Bullen Woreda,

\begin{tabular}{lcl} 
Jan, 2006 & Number (412) & Percent \\
\hline Variable & 284 & \\
\hline Sex & 128 & $68.9 \%$ \\
Male & & $31.1 \%$ \\
Female & 120 & \\
Age & 268 & $29.1 \%$ \\
$10-14$ & 24 & $65 \%$ \\
15019 & & $5.8 \%$ \\
$20-24$ & 188 & \\
Grade & 138 & $45.6 \wedge$ \\
Grade 9 & 50 & $33.5 \%$ \\
Grade 10 & 36 & $12.1 \%$ \\
Grade 11 & $8.7 \%$ \\
Grade 12 & & \\
Religion & 312 & $75.7 \%$ \\
Orthodox Christian & 92 & $22.5 \%$ \\
Protestant & 7 & $1.7 \%$ \\
Muslim & 1 & $0.2 \%$ \\
Others & &
\end{tabular}

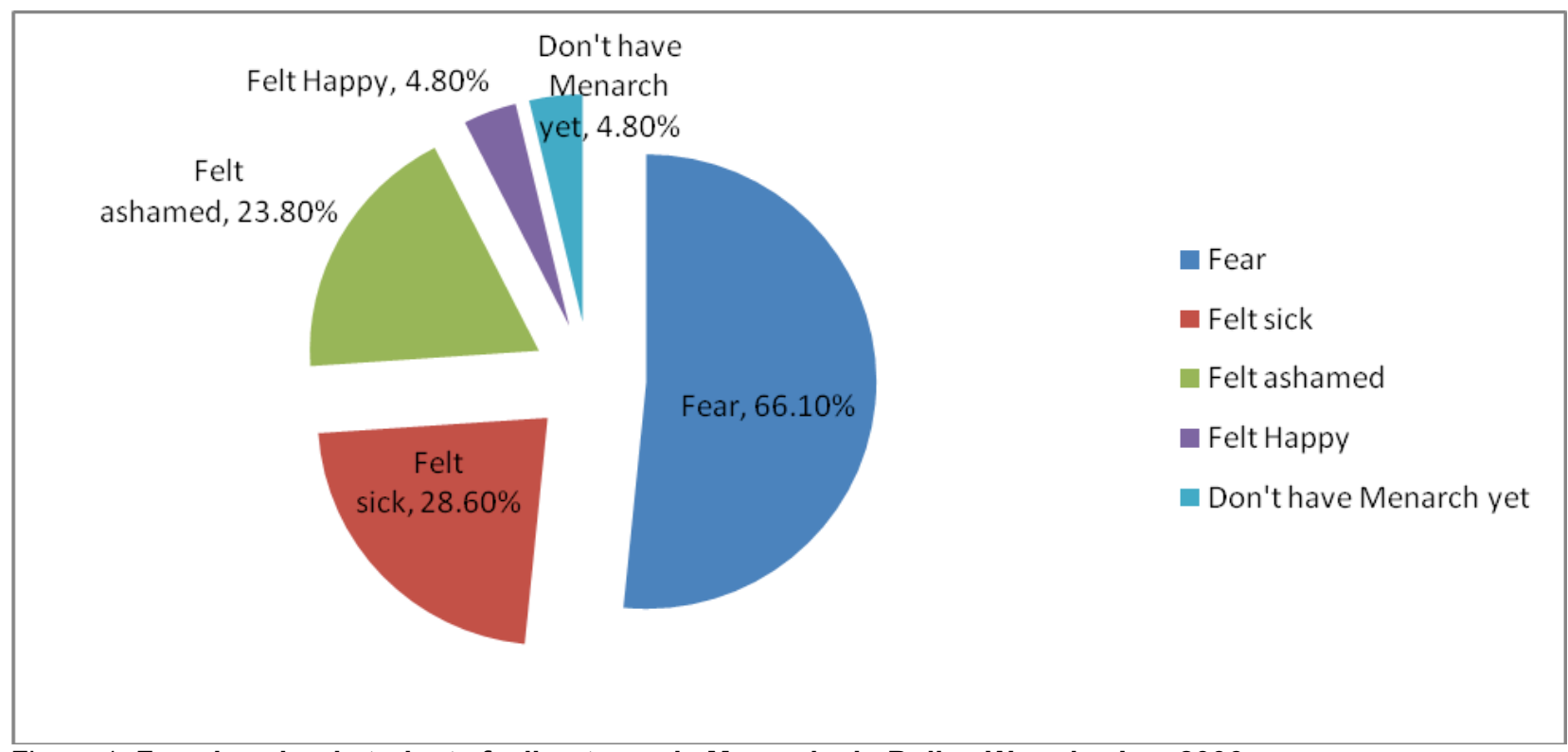

Figure 1: Female school students feeling towards Menarche in Bullen Woreda, Jan, 2006

The most frequently mentioned source of information for SRH were school $335(83.3 \%)$ followed by friends 111 $(27.6 \%)$ (Fig 2).

One hundred fifty three (37.3\%) students believed that it is normal and acceptable to have sexual feeling during adolescence. Out of 412 respondents, 55 (13.3\%) were sexually active. Engaging in sexual activity was reported to be higher $(17.6 \%)$ among males compared to females (3.9\%). The mean age of sexual commencement was $16.1 \pm 2.1 \mathrm{SD}$ and the median was 16 years old. More males reported to have had sexual intercourse than females $(\mathrm{OR}=5 \cdot 3,95 \% \mathrm{CI}=2.0,13.5)$. The majority of the students 381(92.5\%) accepted the importance of education on issues related to sexual and reproductive health to adolescents and three hundred sixty two (88\%) respondents reported that it is important to discuss sexual and reproductive health with parents. However, only one hundred nineteen $(28.9 \%)$ of the students had discussed with either of the parents on at least two topics of sexual and reproductive issues.

One hundred seventy four $(42.2 \%)$ of the students had had discussions related to sexual intercourse. Hundred forty five respondents held discussions with their friends $(83.3 \%)$ and 52 (29.9\%) with brothers (Table 2).

Two hundred fifty $(60.7 \%)$ of the students had discussed about menstrual period. The majority of the students 191 (76.4\%) discussed with their friend followed by teachers 
$93(37.2 \%)$. Females were discussing more frequently than male on menstrual period $(\mathrm{OR}=6.8,95 \% \mathrm{CI}=3.88$, 11.92).

Concerning STI/HIV/AIDS, three hundred twenty four $(78.6 \%)$ of the students reported that they had had discussion on STI/HIV/AIDS. The majority of the students 237 (73.1\%) had discussed this issue with their friends, followed by $113(34.9 \%)$ teachers.

Most of the participants 233 (54.1\%) reported to have had discussion about unwanted pregnancy. One hundred seventy $(76.2 \%)$ of the respondents had discussed with their friends and $84(37.2 \%)$ with their sisters (Table 2$)$.

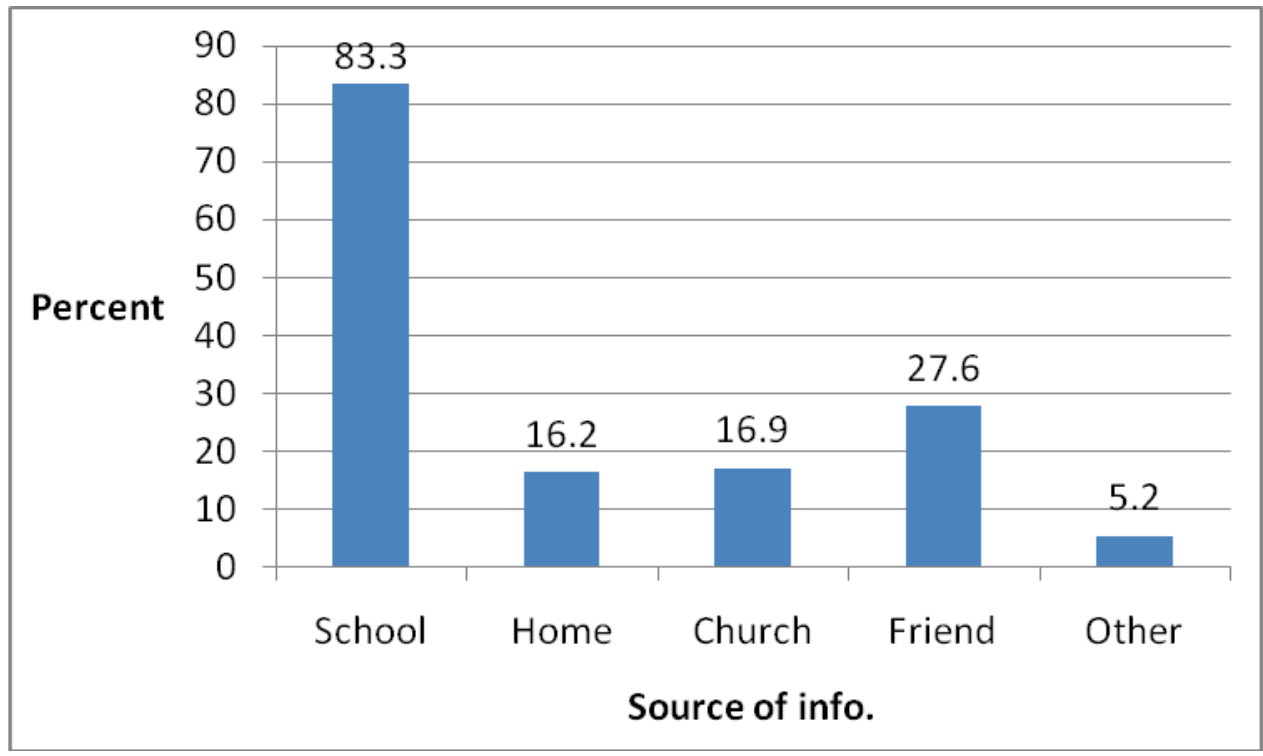

Figure 2: School students' response to source of information for sexual and reproductive health, Bullen Woreda, Ethiopia Jan. 2006.

Table 2: School students, with whom they had discussed in different topics Bullen Woreda, Feb, 2006

\begin{tabular}{|c|c|c|c|c|c|c|c|}
\hline \multirow{2}{*}{$\begin{array}{l}\text { Topic of } \\
\text { discussion }\end{array}$} & \multirow{2}{*}{$\begin{array}{l}\mathbf{N}(\%) \\
\text { discussed } \\
\text { Yes }\end{array}$} & \multicolumn{6}{|c|}{ With whom they had discussed } \\
\hline & & Mother* & Father* & Friend* & Brother* & Sister* & Teacher* \\
\hline Contraceptive & $170(41.3)$ & $63(37.1)$ & $41(24.1)$ & $117(68.8)$ & $51(30)$ & $52(30.6)$ & $58(34.1)$ \\
\hline STI/HIVIAIDS & $324(78.6)$ & $76(23.5)$ & $70(21.6)$ & $237(73.1)$ & $77(23.8)$ & $66(20.4)$ & $113(34.9)$ \\
\hline Sexual intercourse & $174(42.2)$ & $25(14.4)$ & $21(12.1)$ & $145(83.3)$ & $52(29.9)$ & $28(16.1)$ & $43(24.7)$ \\
\hline Unwanted Pregnancy & $233(54.1)$ & $82(36.8)$ & $45(20.2)$ & $170(76.2)$ & $83(37.2)$ & $84(3.7)$ & $80(35.9)$ \\
\hline $\begin{array}{l}\text { Avoiding premarital } \\
\text { sex }\end{array}$ & $227(55.1)$ & $46(20.4)$ & $37(16.4)$ & $197(87.2)$ & $94(41.6)$ & $73(32.3)$ & $64(28.8)$ \\
\hline Condom & $244(59.2)$ & $20(8.3)$ & $17(7.1)$ & $205(85.4)$ & $95(39.6)$ & $40(16.7)$ & $81(33.8)$ \\
\hline Pubertal stage & $309(75.0)$ & $36(11.7)$ & $40(12.9)$ & $243(78.6)$ & $125(40.5)$ & $66(21.4)$ & $140(45.3)$ \\
\hline Menstrual cycle & $250(60.7)$ & 37 (14.8) & $7(2.8)$ & $191(76.4)$ & $52(20.8)$ & $84(33.6)$ & $93(37.2)$ \\
\hline
\end{tabular}

* Multiple responses were possible,

+ Percents are in bracket

On the other hand, two hundred forty four (59.2\%) of the participants claimed to have had discussed about condoms. The majority $205(85.4 \%)$ discussed about it with their friends, followed by brothers 95(39.6\%) and sisters $81(33.8 \%)$.

Regarding the preferred group for discussion about sexual and reproductive health issues, most of the participants $314(76.4 \%$ ) chose their friends followed by brothers 111(27\%), teachers 99(24.1\%), mothers $98(23.8 \%)$, fathers $85(20.7 \%)$, sisters $84(20.4 \%)$ and others $8(1.9 \%)$. Moreover, there were sex preferences in discussing SRH health issues. Both males and females were more comfortable to discuss sexual and reproductive health issues with same sex (Table 3 ).

\section{Summary of Focus Groups Discussion with parents}

Thirty-two parents, out of whom 16 females and 16 males were, involved in four focus group discussions. The focus group discussions were conducted separately for males and females parents. 
Table 3: School students' preference to discuss on sexual and reproductive health issues, in Bullen Woreda, Ethiopia, Jan, 2006

\begin{tabular}{llll}
\hline Preference & Males & Females & **PR (95\% CI) \\
\hline Fathers & $74(26.1 \%)$ & $11(8.6 \%)$ & $\mathbf{3 . 8 ( 1 . 9 - 8 . 2 ) *}$ \\
Mothers & $63(22.3 \%)$ & $35(27.3 \%)$ & $0.8(0.5-1.3)$ \\
Friends & $222(78.4 \%)$ & $92(71.9 \%)$ & $1.4(0.9-2.4)$ \\
Brothers & $100(35.3 \%)$ & $11(8.6 \%)$ & $\mathbf{5 . 8}(\mathbf{2 . 9}-12.5)^{*}$ \\
Sisters & $43(15.2 \%)$ & $41(32 \%)$ & $\mathbf{0 . 4}(\mathbf{0 . 2}-\mathbf{0 . 6})^{*}$ \\
Teachers & $76(54.7 \%)$ & $17(15.3 \%)$ & $\mathbf{2 . 7 ( 1 . 5 - 5 . 0 ) *}$ \\
\hline
\end{tabular}

Most of the parents said that discussion about sexual and reproductive health between adolescents and parents is important for the future life as adults. One of the parents (a father) said that he personally agrees to discuss about $\mathrm{SRH}$, but before discussion with parents they need to have some ideas on importance of discussion on SRH issues at school or elsewhere. "Otherwise our adolescents may not listen to us or consider the discussion worthless". Most of the parents said that they discussed on disease like HIV/AIDS, on formal education/future career and avoiding premarital sex. However, most mothers stated that they had little or no discussion on "sensitive issues" such as menses and sexual intercourse with their adolescents because it is culturally unacceptable and creates discomfort. They said it is inconvenient to discuss such issue in detail. One mother said that she didn't discuss about sexual contact or menses openly but just superficially and in indirect ways. Some thought that talking about this issue in detail may rather encourage or remind adolescents to be engaged in sex. Another issue that was agreed by women participants was that they were afraid that daughters might be unhappy if such issues are discussed since they may think that they are suspected of sexual activities.

All parents also indicated that there is a gap in discussing of the positive aspects of adolescent sexuality related issues, if at all discussed they inclined to negative aspect of sexuality related issues.

Fathers also agreed that they do not discuss sexual and menses issues with their children since it creates discomfort and "it is not culturally acceptable". They stated that it is easier to discuss such issues in detail with sons but never with daughters.

All parents preferred the same sex to discuss sexual and reproductive health related issues with their children.

\section{Discussion}

This study is one of few studies that have attempted to assess communication on sexual and reproductive health issues among preparatory and high school students and their parents in Ethiopia and the first of its kind in Benishangul Gumuz Regional State.

In this study 55(13.3\%) students reported to have had sexual experience. The figure is considerably lower when compared with the result of study done in Ziway high school (south central Ethiopia) students which was $31.5 \%$ (9). This could be related to the rural nature of our study area where the culture may be more restrictive of premarital sex.

Males were about five times more likely than females to be engaged in sexual intercourse $(\mathrm{OR}=5.3,95 \% \mathrm{CI}=2.0$ 13.5). This may be related to the prevailing traditions that encourage premarital male sexual activities.

The mean age of sexual initiation of the respondents of the present study was $16.1 \pm 2.1 \mathrm{SD}$ and it was similar to those reported among senior secondary school students in Accra Ghana 16.0. Our finding is also similar with the studies done in Addis Ababa, and Bahir Dar (10-12).

In this present study adolescents were more comfortable discussing SRH issues with mothers than fathers. However, both female and male adolescents prefer similar sex. This is consistent with the findings of a study in another administrative region in Ethiopia (13). A study done in Emory University, Atlanta Georgia USA, and Mexico showed similar finding that both male and female adolescents were more likely to discuss sexual topics with their mothers than their fathers. Male adolescents were more likely to discuss sex related topics with their fathers than female adolescents $(14,8)$. The Ethiopian study mentioned above and a study in Kenya showed that both male and female adolescents would be most comfortable discussing sexual matters with their friends of same sex and siblings $(13,15,16)$. This is consistent finding with the present study. Thus sex preference is an important issue which needs serious consideration in advocating communication between children and parents.

Most students 314 (76.4\%) preferred to discus SRH issues with friends or peers. It seems that students feel more comfortable and' at ease to discuss SRH issues with friends or peers compared to parents.

Moreover, in this study adolescents reported discussing a number of sex related topics with friends or peers and which supports the importance of peers, the finding is similar with study done in Atlanta Georgia USA (14).

This implies, if peers are not equipped with appropriate information on SRH they may influence each other in negative way whereas if they are equipped with appropriate information on SRH it will have a multiplying effect. Similarly, for many adolescents school and mass media were preferred sources of sexual and reproductive health information. This may suggest that there is a need to equip school friends (peers) and the mass media with the appropriate information and IEC materials on SRH issues. 
The results of the present focus group discussion that parents were having discussions to a greater extent on issues related to future career compared to SRH issues is a comparable finding with the study done in Kenya (10).

The study done in Atlanta Georgia in USA, mentioned above indicated that the content of parentadolescents conversation seemed to focus more on the negative out comes of sexual intercourse and sexuality and low on what adolescents should know to more completely understand how they are growing and developing (14). This finding is also consistent with the FGD conducted in this study, which indicates that there is a gap in discussing the positive aspects of adolescent sexuality related issues. Thus, if discussions with young children are conducted in a negative and threatening way, they will be unlikely to turn to their parents to discuss sexual matters as they get older. On the other hand, positive communication about sexual information, feelings, attitudes, values and behavior when children are young often leads to ongoing discussions as they mature. Establishing an environment conducive to open and comfortable communication is therefore, extremely important.

Majority of the female respondents feeling towards first menstrual cycle /menarche in the present study included fear, followed by, felt sick, and felt shame. This may suggest that most of the female adolescents did not discuss with their parents prior to their menarche, which is also comparable finding with FGD of the present study in which the majority of parents did not discuss on menstrual issues with their female adolescents.

In conclusion, communications on sexual and reproductive health issues both were preferred and took place to a much greater with their friends/peers of similar sex than parents. There was low parent-youth communication on SRH issues. This shows that Sexual and $\mathrm{RH}$ related issues continue to be socio cultural taboos among both young people and their parents.

Thus, while SRH knowledge should be imparted early in the education system to prevent SRH related problems, their consequences and enhance positive peer influence the community should be sensitized to encourage open discussion among family members in general and between parents and children in particular. Steps need to be taken to develop parents communications skills on SRH related issues and introduce Family Life Education (FLE).

Finally, further studies should be conducted to determine effective ways of implementation of parents-adolescents communication under diverse socio-cultural settings on sexuality and reproductive health related issues and the effect of communication on safe sexual behaviors.

\section{Acknowledgements}

We would like to extend our deepest gratitude to Benishangul-Gumuz Regional State HIV/AIDS Prevention and Control Office and Regional Health Bureau for jointly sponsoring this work.

Our appreciation goes to the data collectors, all study participants, zonal and district health offices and participating schools for their cooperation. Our thanks is also extended to $\mathrm{Mr}$ Solomon Fekadie and $\mathrm{Mr}$ Lema Gonfa for offering computer service and assisting in data entry.

\section{References}

1. Lewis M, Volkman F. Clinical aspects of child and adolescents development, third edition 1990:211.

2. WHO. Research on Reproductive Health. Biennial Reports. Geneva: WHO; 2000-2001.

3. Elster AB, Kznets NJ. American guide lines for adolescent preventing services (GAPS), Recommendation and Rationale. 2000

4. Sex education to parents [Cited 1997 Nov 12]: Available from: URL: http://www.pair.com/ grpulse.bt/sepa.htm.

5. Versnel M, Berhane Y, Wendte JF, Johannes.F, Wend F. Sexuality and contraception among never married high school students in Butajira. Ethiop Med J 2002;40(1):46-9.

6. Romero de Castilla Gil RJ, Lora Cerezo MN, Cañete Estrada R. Adolescents and source of sex information: preferences and perceived usefulness, Hospital. Aten primaria. 2001;279(1):12-7.[PubMed Abstract].

7. Holtzman D and Rubinson R. Parent and peer communication effects on AIDS- related behavior among U.S high school students. Family planning perspective. Nov/Dec1995;27(6):237-238.

8. Kiragu K, Obwaka E, Odallo D, Van Hulzen C. Communicating about sex: adolescents and parents in Kenya, AIDS/STD Health Promt Exch. 1996;(3):11-3.

9. Taffa N, Haimanot R, Desalegn S, Tesfaye A, Mohamed K. Do parents and young people communicate on sexual matters? The situation of Family Life Education (FLE) in rural town in Ethiopia. Ethiop J Health Dev 1999;13(3):205-216.

10. Nakkazi D. Family communication about HIV/AIDS and sexual behavior among senior secondary school students in Accra, Ghana. Afri Health Sci 2003;3(1):7-14.

11. Fekadu Z. Causal Sex debuts among female adolescents in Addis Ababa. Ethiop J Health Dev 2001;15(2):109-116.

12. Fantahun M, Chala F. Sexual behavior, Knowledge and attitude to ward HIV/AIDS among out school in Bahir Dar Town, North West Ethiopia: Ethiop Med J 1996;34(4):233-242. 
13. Fikre M. Assessment of parent-adolescent communication on sexual and reproductive health matters in Hwassa Town, SNNPR, Ethiopia [MPH thesis]. Addis Ababa University; 2009.

14. Dilorio C, Kellen M, Hockenberry E. Communication about sexual issues: Mothers, Fathers, and friends. Adolesc Health March 1999;24(30):181-9.
15. Vanphanom S. Parent- youth communication and youth's attitudes and behavior in Vientiane municipality in Lao PDR. Journal of Community Medicine and Primary Health Care June 2005;116 (1):8-13.

16. Kiragu K, Obwaka E, Odallo D, Van Hulzen C. Communicating about sex: adolescents and parents in Kenya. Population Report. Oct 1995;10:17-23. 